\title{
Prognostic impact of pretreatment lymphocyte-to-monocyte ratio in advanced epithelial cancers: a meta-analysis
}

Yiming Mao ${ }^{1,3+}$, Donglai Chen ${ }^{2 \dagger}$, Shanzhou Duan ${ }^{1 \dagger}$, Yuhuan Zhao ${ }^{1}$, Changjiang Wu ${ }^{4}$, Feng Zhu ${ }^{3}$, Chang Chen ${ }^{2^{*}}$ and Yongbing Chen ${ }^{1 *}$

\begin{abstract}
Background: There is increasing evidence that inflammation-based biomarkers are associated with tumor microenvironment which plays important roles in cancer progression. A high lymphocyte-to-monocyte ratio (LMR), has been suggested to indicate favorable prognoses in various epithelial cancers. We performed a meta-analysis to quantify the prognostic value of LMR in advanced-stage epithelial cancers undergoing various treatment.

Methods: We searched PubMed, EMBASE, Web of science and Cochrane Library up to July 2018 for relevant studies. We included studies assessing the prognostic impact of pretreatment LMR on clinical outcomes in patients with advanced-stage epithelial cancers. The primary outcome was overall survival (OS) and the secondary outcome was progression free survival (PFS). The summary hazard ratio (HR) and 95\% confidence interval (Cl) were calculated.

Results: A total of 8984 patients from 35 studies were included. A high pretreatment LMR was associated with favorable OS ( $H R=0.578,95 \% \mathrm{Cl} 0.522-0.641, P<0.001)$ and PFS ( $H R=0.598,95 \% \mathrm{Cl} 0.465-0.768, P<0.001)$. The effect of LMR on OS was observed among various tumor types. A higher pretreatment LMR was associated with improved OS in chemotherapy $(n=10, H R=0.592,95 \% C l 0.518-0.676, P<0.001)$, surgery $(n=10, H R=0.683,95 \% C l 0.579$ $0.807, P<0.001)$ and combined therapy $(n=11, \mathrm{HR}=0.507,95 \% \mathrm{Cl} 0.442-0.582, P<0.001)$ in the subgroup analysis by different therapeutic strategies. The cut-off value for LMR was 3.0 (range $=2.35-5.46$ ). Subgroup analysis according to the cut-off value showed a significant prognostic value of LMR on OS and PFS in both subgroups.

Conclusions: A high pretreatment LMR is associated with favorable clinical outcomes in advanced-stage epithelial cancers undergoing different therapeutic strategies. LMR could be used to improve clinical decision-making regarding treatment in advanced epithelial cancers.
\end{abstract}

Keywords: Lymphocyte-to-monocyte ratio, Prognosis, Epithelial cancer, Treatment

\footnotetext{
*Correspondence: chenthoracic@163.com; chentongt@sina.com

†Yiming Mao, Donglai Chen and Shanzhou Duan equally contributed to the work

${ }^{1}$ Department of Thoracic Surgery, The Second Affiliated Hospital

of Soochow University, 1055 Sanxiang Road, Gusu District,

Suzhou 215004, China

${ }^{2}$ Department of Thoracic Surgery, Shanghai Pulmonary Hospital, Tongji University, School of Medicine, 507 Zhengming Road, Yangpu District,

Shanghai 200433, China

Full list of author information is available at the end of the article
}

(c) The Author(s) 2018. This article is distributed under the terms of the Creative Commons Attribution 4.0 International License (http://creativecommons.org/licenses/by/4.0/), which permits unrestricted use, distribution, and reproduction in any medium, provided you give appropriate credit to the original author(s) and the source, provide a link to the Creative Commons license, and indicate if changes were made. The Creative Commons Public Domain Dedication waiver (http://creativecommons.org/ publicdomain/zero/1.0/) applies to the data made available in this article, unless otherwise stated. 


\section{Background}

Cancer remains the most threatening disease to human health worldwide [1]. Although strides in various therapies to treat advanced-stage cancers have never ceased to be made, the long-term survival of cancer patients remains disappointing. Hitherto, the clinical and pathological staging systems have been the primary references used to predict the outcomes of cancer patients; these systems are based on preoperative imaging or biopsy of tumors rather than the individual data [2]. In addition, current staging systems cannot always accurately predict the risk of recurrence and benefits from neoadjuvant or adjuvant therapy in advanced cancers [2-11]. Therefore, more effective and convenient indicators should be taken as supplementary references to stratify cancer patients and to guide therapeutic strategies.

Currently, there is increasing evidence that inflammation-based biomarkers are associated with tumor microenvironment [12-16], which plays important roles in cancer development, progression and metastasis in epithelial cancers. Inflammatory responses in the tumor microenvironment have been reported to be reflected by some common biomarkers in peripheral blood, especially some cytokines, leukocytes and their subtypes [2, 12, 14, 17]. Therefore inflammation-based biomarkers are potential indicators for the prognoses of cancer patients undergoing different treatments.

Numerous studies have reported that the pretreatment LMR is associated with prognosis in various cancers [17-38]. However, the prognostic impact of LMR in advanced epithelial cancers remains inconclusive. The purpose of this meta-analysis is to investigate the association between pretreatment LMR and the outcomes for advanced-stage epithelial cancers with different therapeutic strategies, on the basis of current evidence.

\section{Methods}

\section{Search strategy}

This meta-analysis was conducted in line with the preferred reporting items for systematic reviews and meta-analyses (PRISMA) statement [39]. Studies were identified by searching databases including PubMed, EMBASE, Web of science and Cochrane Library up to June 2018 without language restrictions. The full search strategies are presented in Additional file 1: Table S1. The reference lists of the previously published meta-analyses were also manually reviewed until no additional potential articles could be identified.

\section{Study selection and inclusion criteria}

The identified studies were selected by two independent reviewers (Mao and Chen). First, the titles and abstracts were screened to assess study the eligibility, and then the full text was reviewed. Any disagreement was resolved by discussion or by a third reviewer (Duan) to reach a consensus. Studies meeting that met the following criteria were included: (1) Studies involving individuals with advanced-stage epithelial tumors and concerning the prognostic value of the pretreatment LMR. The definition of "advanced stage" was derived from the original research from which we extracted data. The timing of assessment of LMR was set at baseline before any treatment was initiated. (2) Studies providing the hazard ratio (HR) with a 95\% confidence interval (CI) for overall survival (OS) or progression-free survival (PFS), or indirect information such as Kaplan-Meier curves used to estimate survival data on the basis of the methods previously described $[2,40-42]$. (3) If the same population was included in two or more studies, only the one study with the largest sample size or the latest information was included. (4) The full text was available. The exclusion criteria were as follows: (1) Non-human research; (2) Case reports, reviews, comments, editorials, letters or conference abstracts; (3) Patients with mesenchymal tumors or hematologic malignancies; (4) Insufficient data for estimating a HR and 95\% CI; (5) LMR included only as a continuous variable rather than a dichotomized variable.

\section{Data extraction and quality assessment}

Two reviewers (Mao and Chen) independently carried out the data extraction from the eligible studies. The following information was recorded for each study: first author's name, year of publication, research region, inclusion period, study design, number of patients, patient age, tumor type, tumor stage, treatment, cut-off value of LMR, time of LMR assessment, follow-up period, study endpoints, analysis of hazard ratios and adjustment variables. The individual HR (with the corresponding 95\% CIs) in the studies was also extracted for OS and PFS to assess the therapeutic efficacy. The HRs were preferentially extracted from multivariate analyses. Any discrepancies between reviewers were resolved by consensus. As the previous studies reported [2, 43, 44], a set of modified predefined criteria was applied to assess the risk of bias of the included studies. The modified predefined criteria are shown in Additional file 1: Table S3. Studies with a score of 7 or higher were defined as high-quality, and those with a score whereas scores of less than 7 were considered low-quality.

\section{Statistical analyses}

General data were analyzed using Statistical Package for Social Sciences (SPSS) software (version 21.0 for Windows). STATA 12.0 software (StatCorp, College Station, TX, USA) was used to conduct the 
meta-analysis. Cochran's $Q$ test and Higgins $I$-squared statistic were used to test the heterogeneity of different studies. A $P$ value of less than 0.1 was considered significant. $I^{2}>50 \%$ was deemed to show substantial heterogeneity [45]. When the heterogeneity was significant, a random-effect model was applied; otherwise, a fixed-effect model was used. Summary HRs were calculated according to the appropriate model depending on the heterogeneity of the included studies. The reasons for inter-study heterogeneity were explored using subgroup analysis. Sensitivity analysis was also conducted by omission of each single study to evaluate the stability of the results. Publication bias was assessed using funnel plots, Begg's and Egger's tests [46, 47]. When publication bias was suggested, Duval and Tweedie trim-and-fill methods were applied for the number of missing studies, and the pooled estimate was recalculated to adjust the primary results [48]. All statistical tests were two-sided, and statistical significance was defined as $P$ less than 0.05 .

\section{Results}

Selection of eligible studies

The flow chart of the literature search is shown in Fig. 1. In summary, our search strategy identified 1613 studies after searching the relevant online databases. We excluded 223 duplicate records from the initial studies. After screening the title and abstracts of 1390 studies, 1171 studies were removed, and another 181 articles were excluded after the assessment of full text. Finally, 35 studies [3-11, 15-38, 49,50] met our inclusion criteria that were selected for the present meta-analysis.

\section{Study characteristics}

These studies included a total of 8984 patients with a median age of 60.6 years and a median follow-up period of 26.8 months. Table 1 and Additional file 1: Table S2 provide the basic and summarized characteristics of the identified studies that met the inclusion criteria. In summary, all studies had a retrospective study design and were published between 2014 and 2018. 12 different kinds of epithelial tumors were included in these studies,

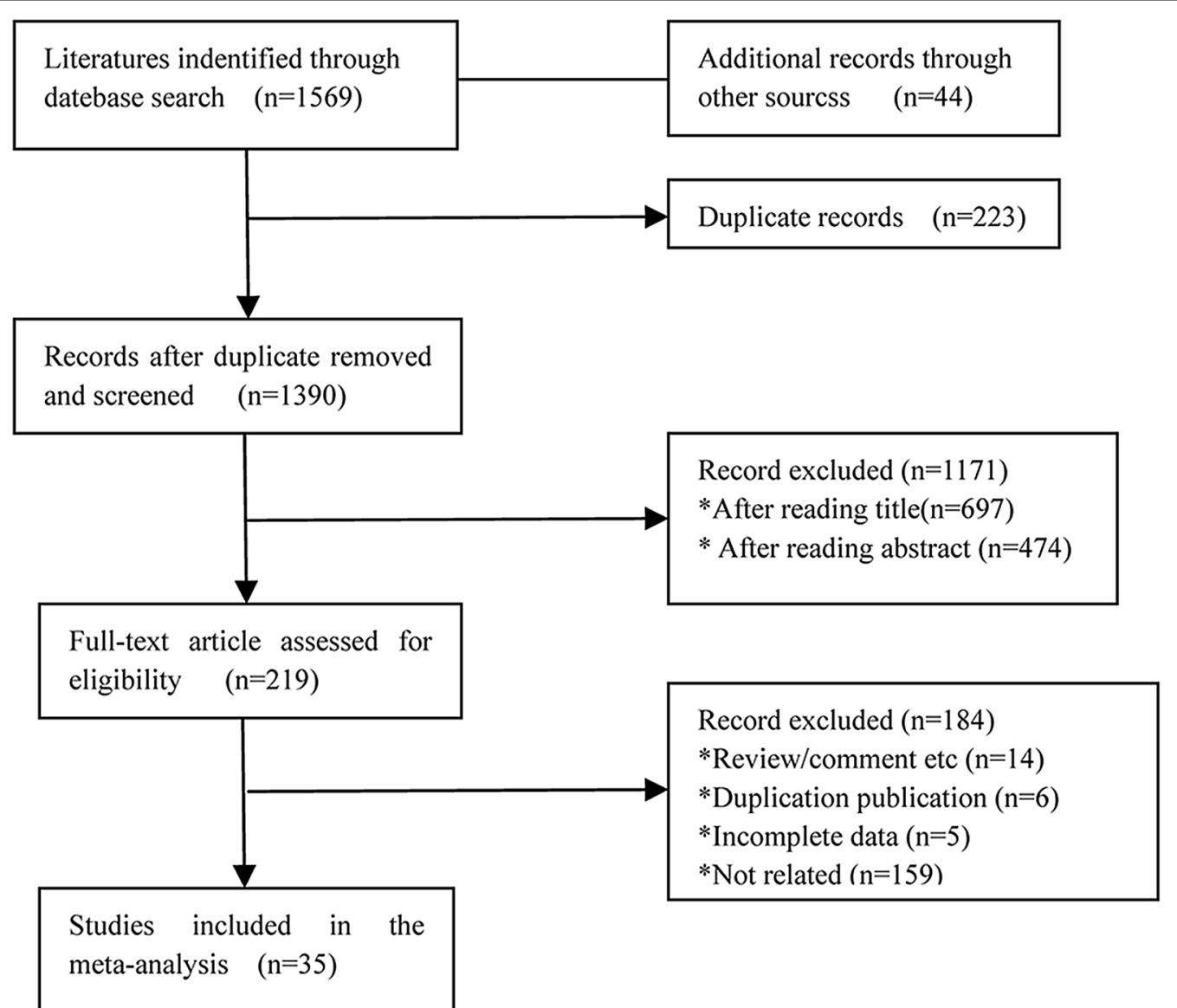

Fig. 1 Literature search of eligible studies 


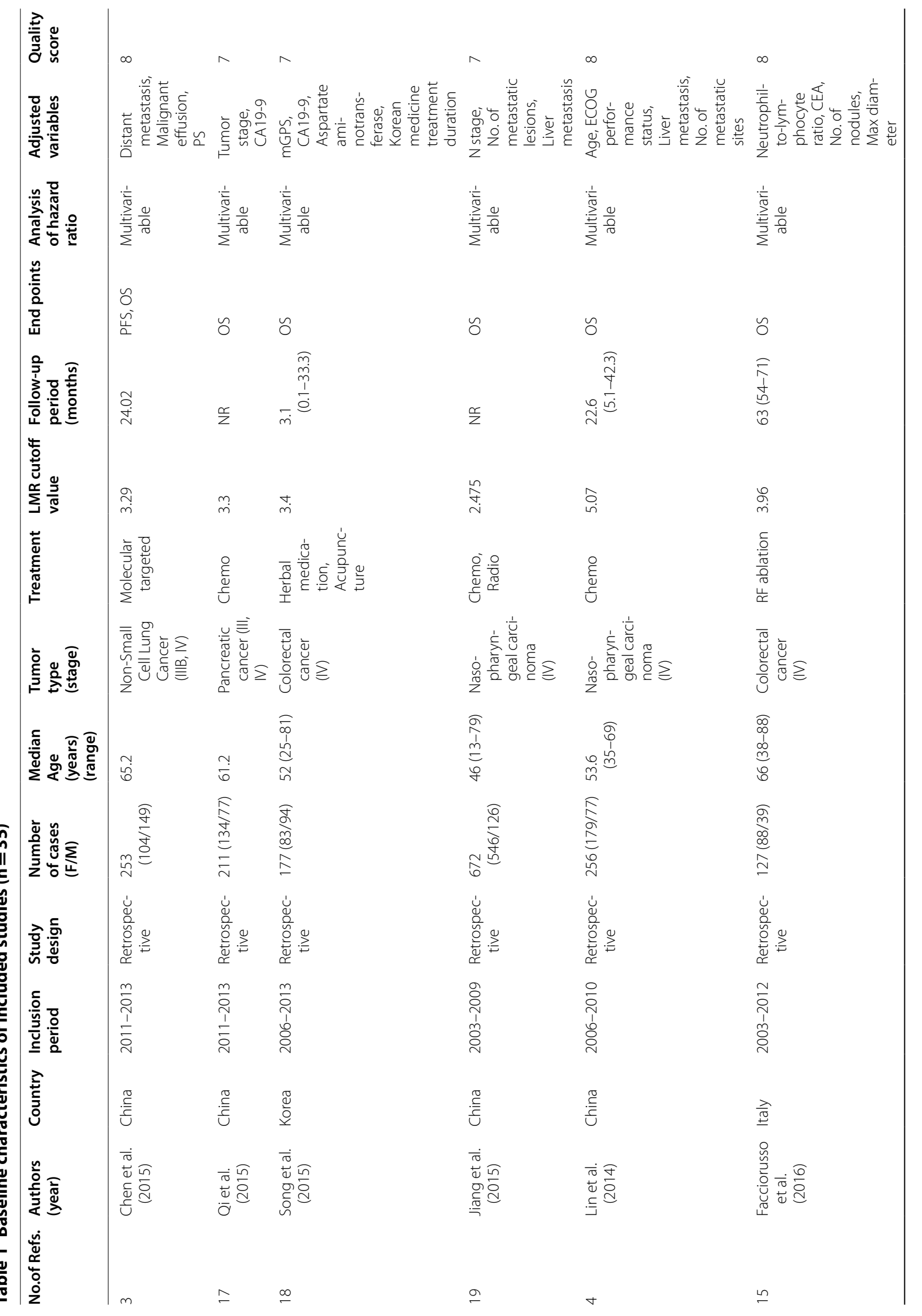




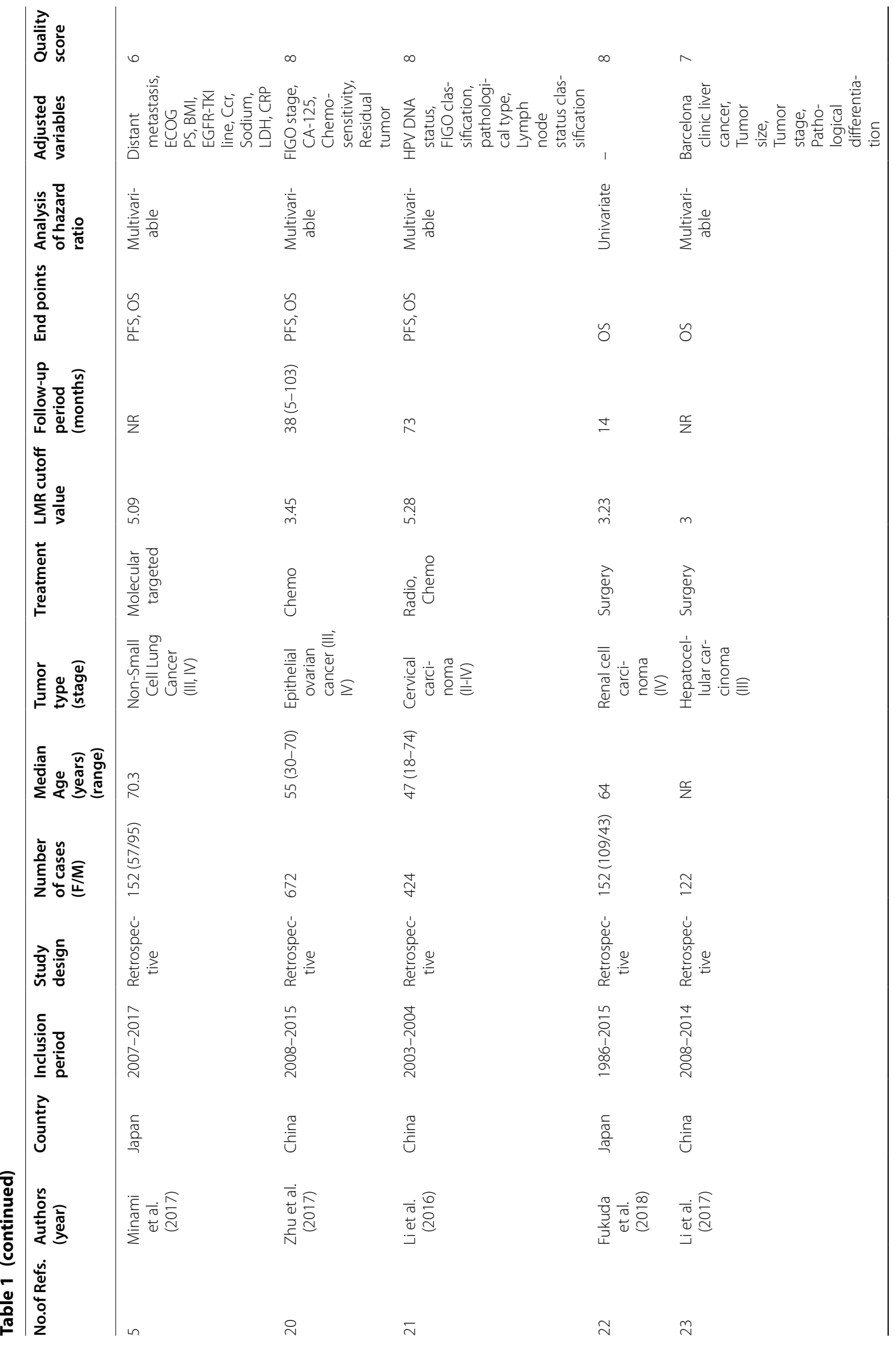




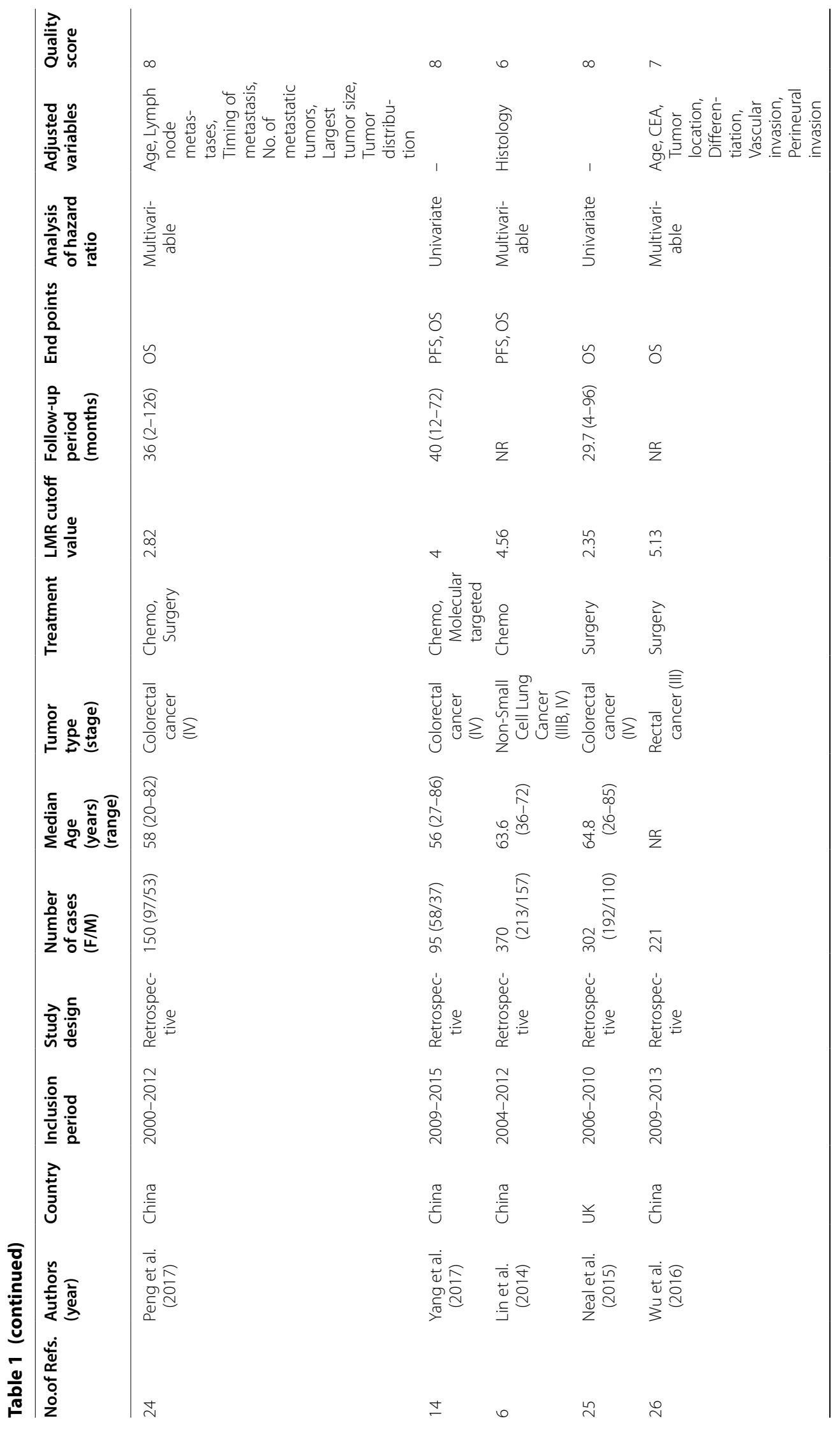




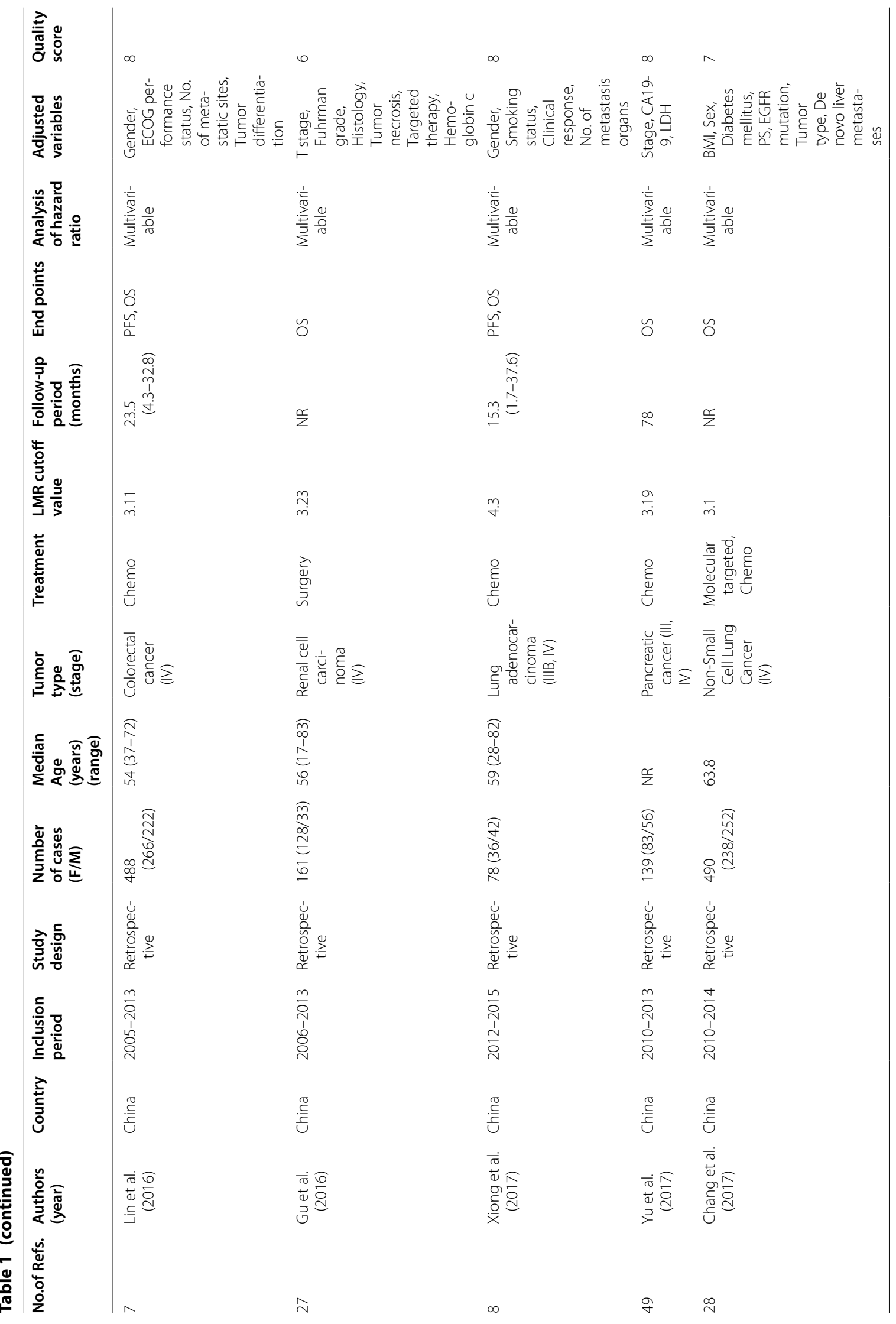




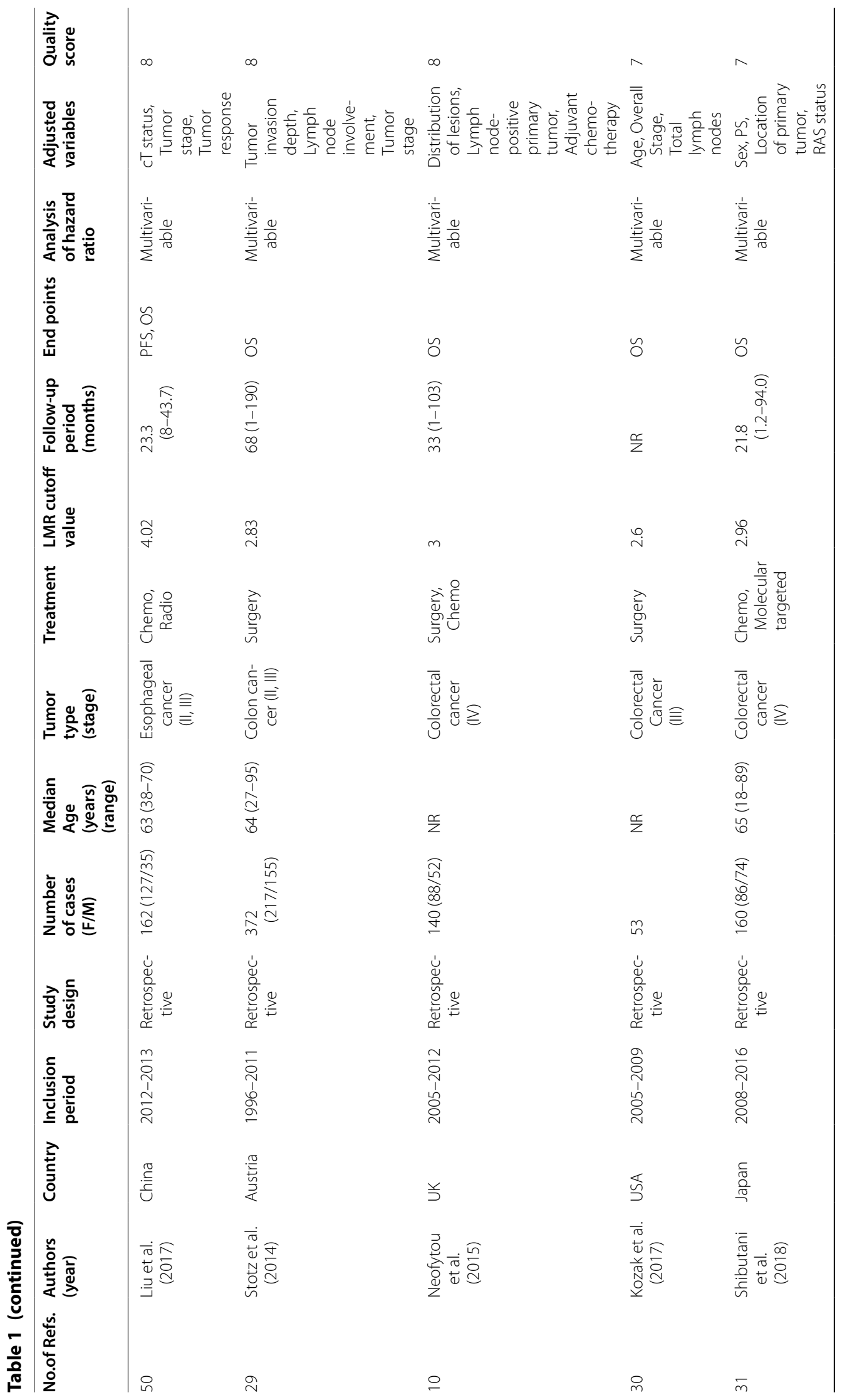




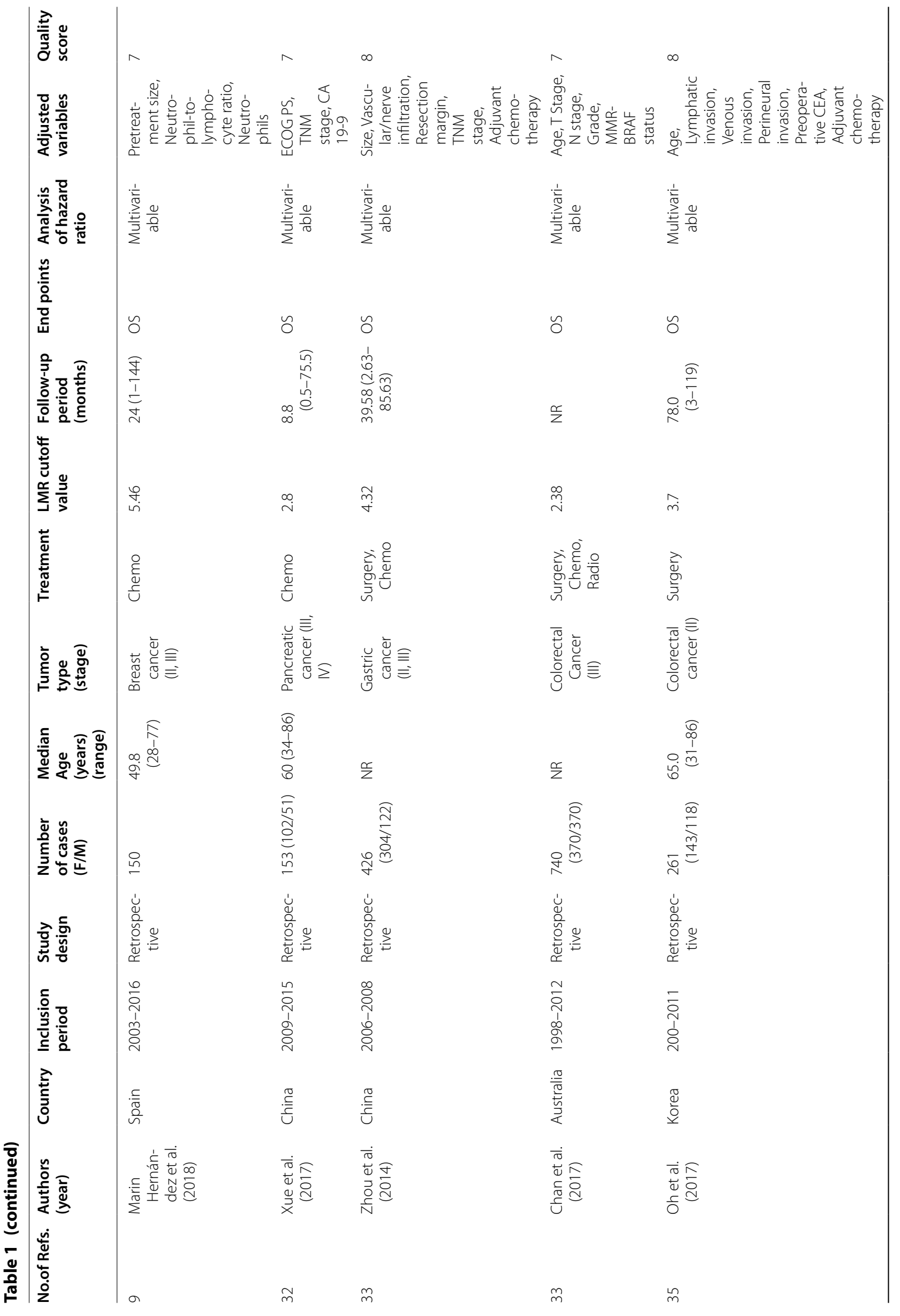




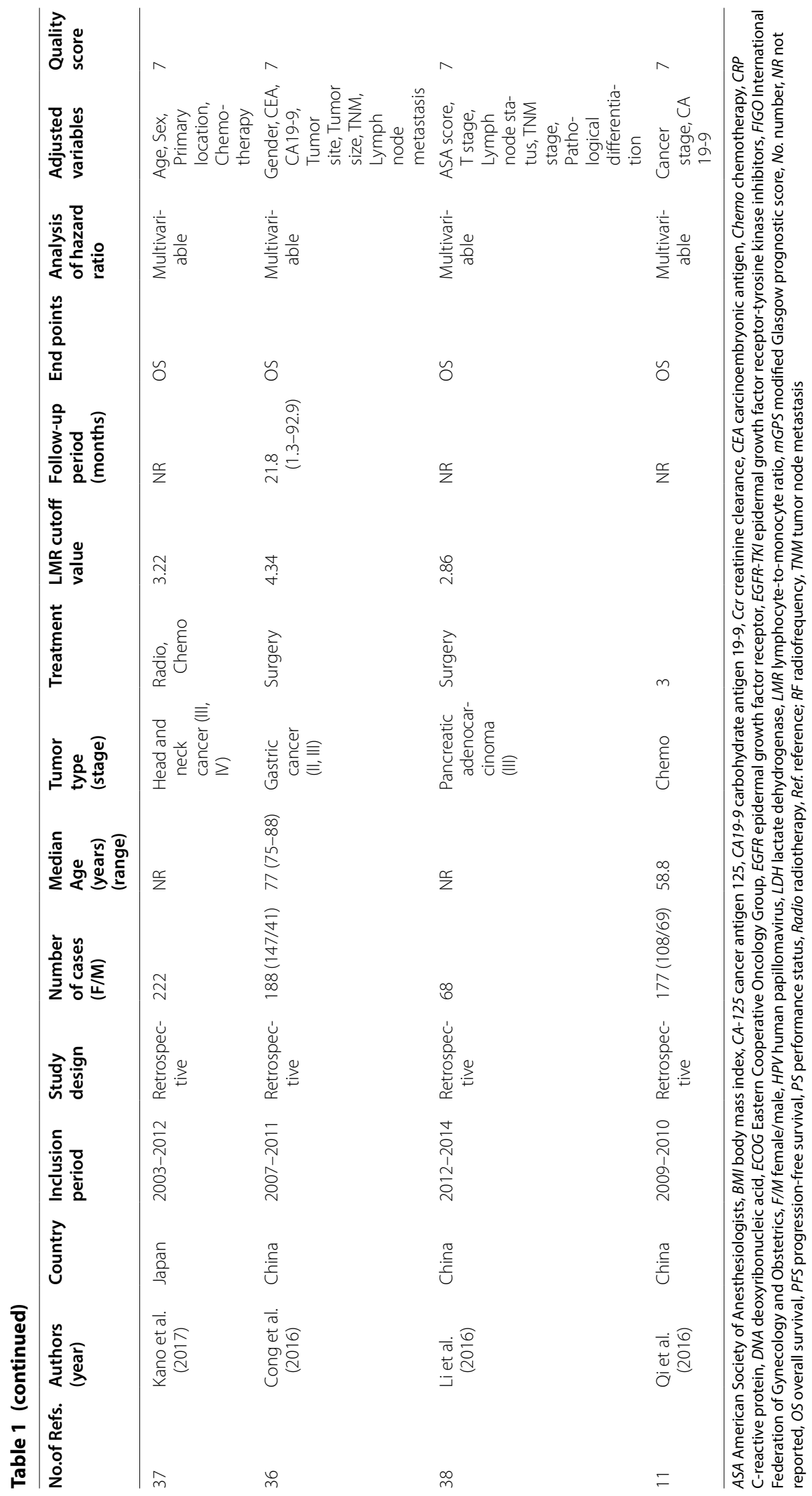


and the median number of patients was 177 . Colorectal cancer and lung cancer were the two main types of cancers. The main therapeutic strategies included chemotherapy, surgery and combined therapy. 28 studies were conducted in Asia, 5 in Europe and 2 in America and others. The association between pretreatment LMR and OS was investigated in all the included studies, among which 9 also investigated the association between pretreatment LMR and PFS as well. The median cut-off value for LMR was 3.23. Most of the included studies (32/35) used multivariate analysis method to adjust covariates when analyzing the prognostic value of LMR. According to the risk assessment scale, 3 studies had quality scores less than 7 , the other 32 had a score more than 7 (Additional file 1: Table S3).

\section{Primary outcome: overall survival}

35 studies with 8984 individuals were included in the analysis of pretreatment LMR and OS. Figure 2a indicates that a higher pretreatment LMR was associated with improved OS ( $\mathrm{HR}=0.578,95 \%$ CI $0.522-0.641$, $P<0.001)$. Given that the test for heterogeneity was significant $\left(Q=113.56, P<0.001, I^{2}=70.1 \%\right)$, a randomeffect model was used. Subgroup analyses were applied to explore potential sources of heterogeneity among several related clinical features for OS (Table 2). The pooled HRs of most subgroups were markedly changed in subgroup analyses. The subgroup analysis by tumor types showed a higher pretreatment LMR was significantly associated with better OS in colorectal cancer $(\mathrm{n}=13$, $\mathrm{HR}=0.579,95 \%$ CI $0.516-0.650, I^{2}=0 \%$ ), lung cancer $\left(\mathrm{n}=5, \mathrm{HR}=0.594,95 \%\right.$ CI $\left.0.435-0.811, I^{2}=85.5 \%\right)$, pancreatic cancer $(\mathrm{n}=5, \mathrm{HR}=0.588,95 \%$ CI $0.407-0.851$,
$\left.I^{2}=67.9 \%\right)$, gastric cancer $(\mathrm{n}=2, \mathrm{HR}=0.664,95 \% \mathrm{CI}$ $\left.0.523-0.843, I^{2}=0 \%\right)$, nasopharyngeal carcinoma $(\mathrm{n}=2$, $\mathrm{HR}=0.479,95 \%$ CI $0.406-0.566, I^{2}=0 \%$ ), renal cancer $\left(\mathrm{n}=2, \mathrm{HR}=0.827,95 \%\right.$ CI $\left.0.755-0.906, I^{2}=0 \%\right)$, cervical carcinoma $(\mathrm{n}=1, \mathrm{HR}=0.337,95 \%$ CI $0.164-0.691)$, ovarian cancer $(\mathrm{n}=1, \mathrm{HR}=0.615,95 \%$ CI $0.527-0.718)$, esophageal cancer $(\mathrm{n}=1, \mathrm{HR}=0.495,95 \%$ CI 0.315 $0.778)$ and head and neck cancer $(n=1, H R=0.28,95 \%$ CI 0.168-0.466), but not breast cancer $(\mathrm{n}=1, \mathrm{HR}=0.47$, 95\% CI 0.171-1.295, $P=0.144$ ) and hepatocellular carcinoma $(\mathrm{n}=1, \mathrm{HR}=0.73,95 \%$ CI $0.399-1.336, P=0.308)$. To be noted, the subgroup analysis by different therapeutic strategies indicated that a higher pretreatment LMR was associated with improved OS in chemotherapy $(\mathrm{n}=10, \mathrm{HR}=0.592,95 \%$ CI $0.518-0.676, P<0.001)$, surgery $\quad(\mathrm{n}=10, \quad H R=0.683, \quad 95 \%$ CI $0.579-0.807$, $P<0.001)$, combined therapy $(\mathrm{n}=11, \mathrm{HR}=0.507,95 \%$ CI $0.442-0.582, P<0.001)$ which consists of surgery and (neo)adjuvant therapy. The cut-off values of LMR in the studies ranged from 2.35 to 5.46. After stratifying the cut-off values of LMR into two subgroups, $<3.0$ and $\geq 3.0$, we noted that the level of statistical heterogeneity $\left(<3.0, I^{2}=16 \%\right.$; $\left.\geq 3.0, I^{2}=69.8 \%\right)$ was reduced, while the pooled HRs were not significantly altered. The reduction in statistical heterogeneity was also realized after adjusting research region (Asia, $I^{2}=74.9 \%$; Europe, $I^{2}=0 \%$; America and others, $I^{2}=0 \%$ ), number of cases $\left(<200, I^{2}=63.2 \%\right.$; $\left.>200, I^{2}=41.3 \%\right)$, therapeutic strategies (Chemotherapy, $I^{2}=31.9 \%$; Molecular targeted, $I^{2}=93 \%$; Surgery, $I^{2}=54.3 \%$; Combined therapy, $I^{2}=37.9 \%$; others, $\left.I^{2}=0 \%\right)$ and follow-up period $(\leq 33$, $I^{2}=67.8 \% ;>33, I^{2}=15.6 \%$; NR, $\left.I^{2}=81.1 \%\right)$. Meanwhile, the subgroup analysis by publication year, initial
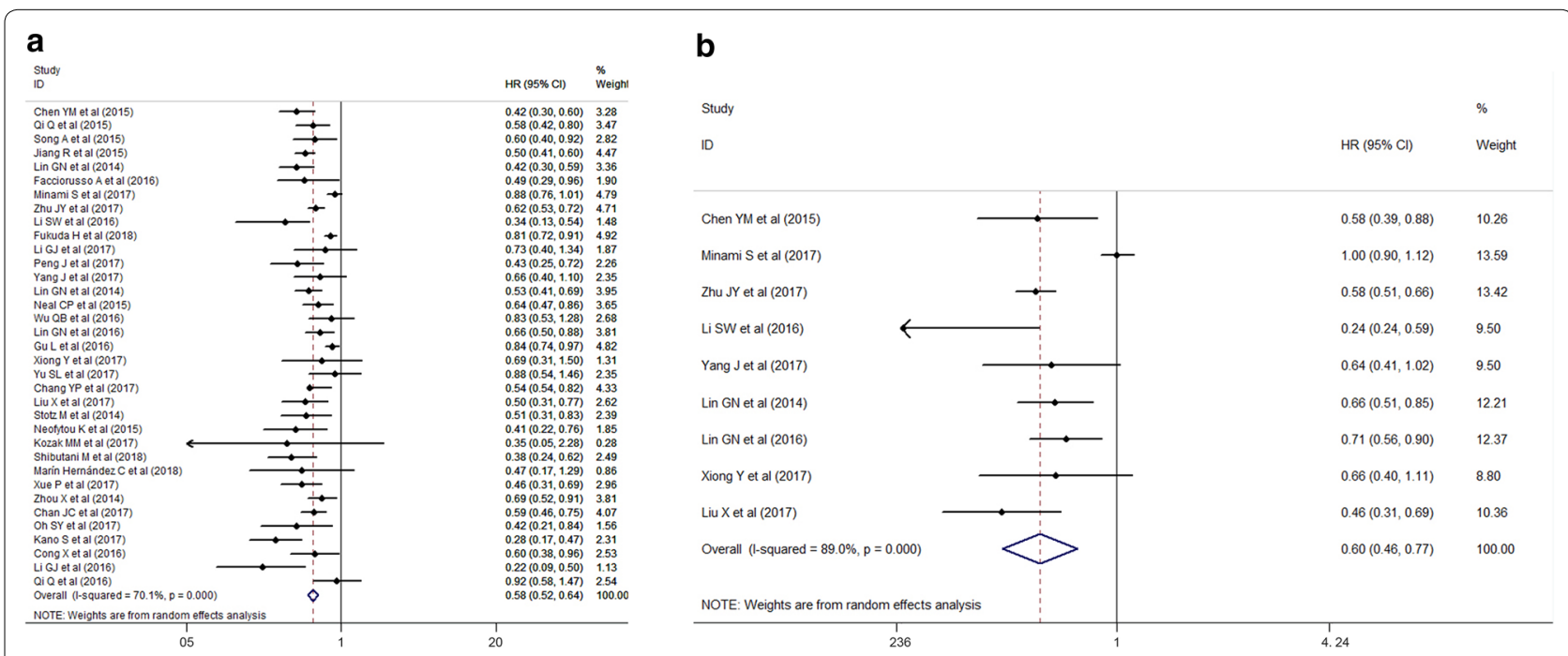

Fig. 2 Meta-analysis of the associations between pretreatment blood LMR and a overall survival; b progression-free survival 
Table 2 Subgroup Analyses of the Associations between LMR and overall survival

\begin{tabular}{|c|c|c|c|c|c|c|}
\hline \multirow[t]{2}{*}{ Variables } & \multirow[t]{2}{*}{ No. of studies } & \multicolumn{3}{|c|}{ Test of association } & \multicolumn{2}{|c|}{ Test of heterogeneity } \\
\hline & & HR & $95 \% \mathrm{Cl}$ & $P$ value & $P^{2}(\%)$ & $P$ value \\
\hline Total & 35 & 0.578 & $0.522-0.641$ & $<0.001$ & 70.10 & $<0.001$ \\
\hline \multicolumn{7}{|l|}{ Publication year } \\
\hline$\leq 2016$ & 18 & 0.572 & $0.497-0.660$ & $<0.001$ & 67.20 & $<0.001$ \\
\hline$>2016$ & 17 & 0.583 & $0.499-0.681$ & $<0.001$ & 72.60 & $<0.001$ \\
\hline \multicolumn{7}{|l|}{ Initial inclusion period } \\
\hline$\leq 2006$ & 19 & 0.554 & $0.480-0.640$ & $<0.001$ & 72.90 & $<0.001$ \\
\hline$>2006$ & 16 & 0.604 & $0.516-0.707$ & $<0.001$ & 68.20 & $<0.001$ \\
\hline \multicolumn{7}{|l|}{ Research region } \\
\hline Asia & 28 & 0.584 & $0.520-0.656$ & $<0.001$ & 74.90 & $<0.001$ \\
\hline Europe & 5 & 0.553 & $0.446-0.685$ & $<0.001$ & 0.00 & 0.712 \\
\hline America and others & 2 & 0.584 & $0.459-0.744$ & $<0.001$ & 0.00 & 0.596 \\
\hline \multicolumn{7}{|l|}{ Number of cases } \\
\hline$<200$ & 19 & 0.632 & $0.547-0.730$ & $<0.001$ & 63.20 & $<0.001$ \\
\hline$>200$ & 16 & 0.549 & $0.497-0.606$ & $<0.001$ & 41.30 & 0.043 \\
\hline \multicolumn{7}{|l|}{ Median age (years) } \\
\hline$\leq 60$ & 13 & 0.585 & $0.496-0.691$ & $<0.001$ & 69.20 & $<0.001$ \\
\hline$>60$ & 13 & 0.575 & $0.488-0.679$ & $<0.001$ & 75.70 & $<0.001$ \\
\hline NR & 9 & 0.557 & $0.427-0.727$ & $<0.001$ & 62.60 & 0.006 \\
\hline \multicolumn{7}{|l|}{ Tumor types } \\
\hline Breast cancer & 1 & 0.47 & $0.171-1.295$ & 0.144 & - & - \\
\hline Cervical carcinoma & 1 & 0.337 & $0.164-0.691$ & 0.003 & - & - \\
\hline Colon cancer and rectal cancer & 13 & 0.579 & $0.516-0.650$ & $<0.001$ & 0.00 & 0.496 \\
\hline Ovarian cancer & 1 & 0.615 & $0.527-0.718$ & $<0.001$ & - & - \\
\hline Esophageal cancer & 1 & 0.495 & $0.315-0.778$ & 0.002 & - & - \\
\hline Gastric cancer & 2 & 0.664 & $0.523-0.843$ & 0.001 & 0.00 & 0.622 \\
\hline Head and neck cancer & 1 & 0.28 & $0.168-0.466$ & $<0.001$ & - & - \\
\hline Hepatocellular carcinoma & 1 & 0.73 & $0.399-1.336$ & 0.308 & - & - \\
\hline Lung cancer & 5 & 0.594 & $0.435-0.811$ & 0.001 & 85.50 & $<0.001$ \\
\hline Nasopharyngeal carcinoma & 2 & 0.479 & $0.406-0.566$ & $<0.001$ & 0.00 & 0.379 \\
\hline Pancreatic cancer & 5 & 0.588 & $0.407-0.851$ & 0.005 & 67.90 & 0.014 \\
\hline Renal cancer & 2 & 0.827 & $0.755-0.906$ & $<0.001$ & 0.00 & 0.7 \\
\hline \multicolumn{7}{|l|}{ LMR cutoff } \\
\hline$<3.0$ & 9 & 0.508 & $0.444-0.582$ & $<0.001$ & 16.00 & 0.3 \\
\hline$\geq 3.0$ & 26 & 0.612 & $0.546-0.686$ & $<0.001$ & 69.80 & $<0.001$ \\
\hline \multicolumn{7}{|l|}{ Therapeutic strategies } \\
\hline Chemotherapy & 10 & 0.592 & $0.518-0.676$ & $<0.001$ & 31.90 & 0.153 \\
\hline Molecular targeted & 2 & 0.622 & $0.304-1.271$ & 0.193 & 93.00 & $<0.001$ \\
\hline Surgery & 10 & 0.683 & $0.579-0.807$ & $<0.001$ & 54.30 & 0.02 \\
\hline Combined therapy & 11 & 0.507 & $0.442-0.582$ & $<0.001$ & 37.90 & 0.097 \\
\hline Others & 2 & 0.563 & $0.400-0.794$ & 0.001 & 0.00 & 0.577 \\
\hline \multicolumn{7}{|l|}{ Follow-up period (months) } \\
\hline$\leq 33$ & 13 & 0.545 & $0.454-0.653$ & $<0.001$ & 67.80 & $<0.001$ \\
\hline$>33$ & 9 & 0.594 & $0.515-0.685$ & $<0.001$ & 15.60 & 0.303 \\
\hline NR & 13 & 0.606 & $0.504-0.729$ & $<0.001$ & 81.10 & $<0.001$ \\
\hline \multicolumn{7}{|l|}{ Quality score } \\
\hline$<7$ & 3 & 0.753 & $0.592-0.958$ & 0.021 & 83.20 & 0.003 \\
\hline$\geq 7$ & 32 & 0.558 & $0.504-0.619$ & $<0.001$ & 58.30 & $<0.001$ \\
\hline \multicolumn{7}{|l|}{ Analysis of hazard ratio } \\
\hline Multivariate & 32 & 0.562 & $0.503-0.628$ & $<0.001$ & 68.70 & $<0.001$ \\
\hline Univariate & 3 & 0.755 & $0.643-0.887$ & 0.001 & 23.30 & 0.272 \\
\hline
\end{tabular}

$C I$ confidence interval, $H R$ hazard ratio, No. number, LMR lymphocyte-to-monocyte ratio 


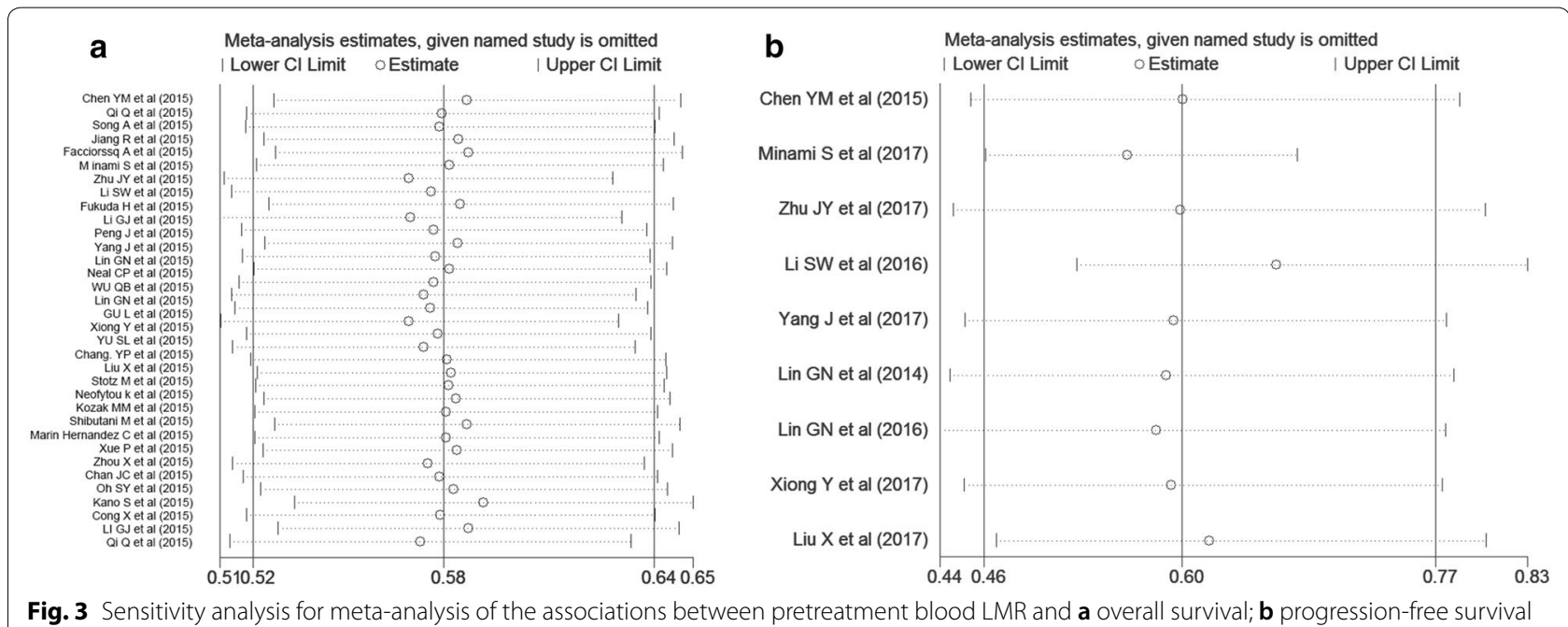

inclusion period, median age, quality score and analysis of HR indicated that a high pretreatment LMR was consistently associated with superior OS.

Sensitivity analysis on the stability of the OS subset indicated that omitting any single study did not significantly affect the pooled HRs (Fig. 3a). As shown in Additional file 2: Figure S1A, the asymmetrical funnel plot suggested that there could be publication bias. It was further confirmed with Egger's test (Begg's test, $P=0.334$; Egger's test, $P<0.001)$. The adjusted random effects pooled HRs of 0.578 (95\% CI 0.522-0.641), obtained using the trim-and-fill method, which was consistent with our primary analysis (Additional file 1: Table S4). The funnel plot adjusted with trim-and-fill methods was shown in Additional file 2: Figure S1B.

\section{Secondary outcome: progression-free survival}

Nine studies with 2694 individuals were included in the analysis of pretreatment LMR and PFS. Figure $2 \mathrm{~b}$ demonstrates that a high pretreatment LMR was associated with longer PFS (HR $=0.598,95 \%$ CI $0.465-0.768$, $P<0.001)$. Since the test for heterogeneity was significant $\left(Q=72.92, P<0.001, I^{2}=89.0 \%\right)$, a random-effect model was used. Table 3 gives the results of subgroup analyses on potential sources of heterogeneity among several related clinical features of the included studies for PFS. The subgroup analysis by tumor types indicated that a higher pretreatment LMR was significantly associated with better PFS in colorectal cancer $(n=2, H R=0.695$, 95\% CI 0.562-0.861, $\left.I^{2}=0 \%\right)$, cervical carcinoma $(\mathrm{n}=1$, $\mathrm{HR}=0.239,95 \%$ CI $0.151-0.379)$, ovarian cancer $(\mathrm{n}=1$, $\mathrm{HR}=0.581,95 \%$ CI $0.508-0.664)$ and esophageal cancer $(\mathrm{n}=1, \mathrm{HR}=0.461,95 \%$ CI $0.31-0.685)$ but not lung cancer $\left(\mathrm{n}=4, \mathrm{HR}=0.738,95 \%\right.$ CI $0.54-1.007, I^{2}=80.00 \%$,
$P=0.056$ ). A higher pretreatment LMR was proved to be associated with improved PFS in the subgroup analysis by different therapeutic strategies including chemotherapy $(\mathrm{n}=4, \mathrm{HR}=0.62,95 \%$ CI $0.558-0.688, P<0.001)$ and combined therapy $(\mathrm{n}=3, \mathrm{HR}=0.415,95 \%$ CI $0.241-$ $0.716, P=0.002$ ). The cut-off values of LMR ranged from 3.11 to 5.28 in different studies. The pooled HRs were not significantly altered by stratifying the cut-off values of LMR into 2 subgroups: $\leq 4.0$ and $>4.0$, which decreased the level of statistical heterogeneity $\left(\leq 4.0, I^{2}=0 \%\right.$; $>4.0$, $\left.I^{2}=92.2 \%\right)$ nonetheless. It was noted that the significant difference was altered in subgroup analysis by number of cases $(<200, P=0.075)$, therapeutic strategies (molecular targeted, $P=0.384$ ), follow-up period (NR, $P=0.356$ ), quality score $(<7, P=0.356)$ and analysis of hazard ratio (Univariate, $P=0.061$ ). Sensitivity analysis further confirmed that omitting any single study did not significantly affect the pooled HRs, exhibiting good stability of PFS subset (Fig. 3b).

\section{Discussion}

A low LMR was first reported to be a poor prognostic indicator in patients with hematologic malignancies [51]. In recent years, several meta-analysis were performed to analyze the relationship between LMR and clinical outcomes of non-hematologic solid tumors [51, 52]. Nishijima et al. first performed a meta-analysis to quantify the prognostic value of pretreatment LMR in non-hematologic solid tumors without incorporating any confounding variable at the patient level or quality of studies into their analysis [51]. Teng et al. carried out another study on the same theme, by using advanced statistical methods, while not making subgroup analysis on different 
Table 3 Subgroup Analyses of the Associations between LMR and progression free survival

\begin{tabular}{|c|c|c|c|c|c|c|}
\hline \multirow[t]{2}{*}{ Variables } & \multirow[t]{2}{*}{ No. of studies } & \multicolumn{3}{|c|}{ Test of association } & \multicolumn{2}{|c|}{ Test of heterogeneity } \\
\hline & & HR & $95 \% \mathrm{Cl}$ & $P$ value & $I^{2}(\%)$ & $P$ value \\
\hline Total & 9 & 0.598 & $0.465-0.768$ & $<0.001$ & 89.00 & $<0.001$ \\
\hline \multicolumn{7}{|l|}{ Publication year } \\
\hline$\leq 2016$ & 4 & 0.526 & $0.355-0.777$ & 0.001 & 83.10 & $<0.001$ \\
\hline$>2016$ & 5 & 0.66 & $0.470-0.881$ & 0.006 & 89.60 & $<0.001$ \\
\hline \multicolumn{7}{|l|}{ Initial inclusion period } \\
\hline$\leq 2006$ & 3 & 0.502 & $0.299-0.843$ & 0.009 & 88.70 & $<0.001$ \\
\hline$>2006$ & 6 & 0.648 & $0.47-0.882$ & 0.006 & 89.60 & $<0.001$ \\
\hline \multicolumn{7}{|l|}{ Nationality } \\
\hline China & 8 & 0.561 & $0.466-0.675$ & $<0.001$ & 64.40 & 0.006 \\
\hline Japan & 1 & 1 & $0.896-1.116$ & 1 & - & - \\
\hline \multicolumn{7}{|l|}{ Number of cases } \\
\hline$<200$ & 4 & 0.684 & $0.450-1.040$ & 0.075 & 83.10 & $<0.001$ \\
\hline$>200$ & 5 & 0.551 & $0.429-0.707$ & $<0.001$ & 77.60 & 0.001 \\
\hline \multicolumn{7}{|l|}{ Median age (years) } \\
\hline$\leq 60$ & 5 & 0.546 & $0.408-0.729$ & $<0.001$ & 77.00 & 0.002 \\
\hline$>60$ & 4 & 0.67 & $0.462-0.971$ & 0.035 & 87.70 & $<0.001$ \\
\hline \multicolumn{7}{|l|}{ Tumor types } \\
\hline Cervical carcinoma & 1 & 0.239 & $0.151-0.379$ & $<0.001$ & - & - \\
\hline Colon cancer and rectal cancer & 2 & 0.695 & $0.562-0.861$ & 0.001 & 0.00 & 0.713 \\
\hline Ovarian cancer & 1 & 0.581 & $0.508-0.664$ & $<0.001$ & - & - \\
\hline Esophageal cancer & 1 & 0.461 & $0.31-0.685$ & $<0.001$ & - & - \\
\hline Lung cancer & 4 & 0.738 & $0.54-1.007$ & 0.056 & 80.00 & 0.002 \\
\hline \multicolumn{7}{|l|}{ LMR cutoff } \\
\hline$\leq 4.0$ & 4 & 0.609 & $0.546-0.680$ & $<0.001$ & 0.00 & 0.546 \\
\hline$>4.0$ & 5 & 0.56 & $0.351-0.892$ & 0.015 & 92.20 & $<0.001$ \\
\hline \multicolumn{7}{|l|}{ Therapeutic strategies } \\
\hline Chemotherapy & 4 & 0.62 & $0.558-0.688$ & $<0.001$ & 0.00 & 0.489 \\
\hline Molecular targeted & 2 & 0.793 & $0.472-1.335$ & 0.384 & 84.10 & 0.012 \\
\hline Combined therapy & 3 & 0.415 & $0.241-0.716$ & 0.002 & 78.40 & 0.01 \\
\hline \multicolumn{7}{|l|}{ Follow-up period (month) } \\
\hline$\leq 33$ & 4 & 0.619 & $0.510-0.751$ & $<0.001$ & 14.20 & 0.321 \\
\hline$>33$ & 3 & 0.457 & $0.270-0.774$ & 0.004 & 85.40 & 0.001 \\
\hline NR & 2 & 0.826 & $0.55-1.239$ & 0.356 & 88.50 & 0.003 \\
\hline \multicolumn{7}{|l|}{ Quality score } \\
\hline$<7$ & 2 & 0.826 & $0.550-1.239$ & 0.356 & 88.50 & 0.003 \\
\hline$\geq 7$ & 7 & 0.542 & $0.435-0.674$ & $<0.001$ & 67.80 & 0.005 \\
\hline \multicolumn{7}{|l|}{ Analysis of hazard ratio } \\
\hline Multivariate & 8 & 0.592 & $0.452-0.776$ & $<0.001$ & 90.40 & $<0.001$ \\
\hline Univariate & 1 & 0.644 & $0.406-1.021$ & 0.061 & - & - \\
\hline
\end{tabular}

Cl confidence interval, $H R$ hazard ratio, No. number; LMR lymphocyte-to-monocyte ratio

therapeutic strategies [52]. Furthermore, given that solid cancers originate from either epithelium or mesenchyme, it is reasonable and necessary to further assess the prognostic value of LMR in advanced-stage epithelial cancers.

To our best knowledge, this is the first meta-analysis to evaluate the association between LMR and outcomes of advanced epithelial cancer patients including the search results from 4 available databases online. We included 35 studies comprising 8984 patients with advanced epithelial tumors and found that a high pretreatment LMR was associated with favorable $\mathrm{OS}(\mathrm{HR}=0.578,95 \% \mathrm{CI}$ $0.522-0.641, P<0.001)$ and PFS $(\mathrm{HR}=0.598,95 \% \mathrm{CI}$ 
0.465-0.768, $P<0.001)$. Furthermore, subgroup analyses were based on publication year, types of cancers, cutoff value, median age, initial inclusion period, research region, treatment, follow-up period, quality score and analysis of hazard ratio. The association between pretreatment LMR and OS remained mostly constant in various subgroups. Notably, the pooled HRs as well as 95\% CI were statistically significant in the subgroups of therapeutic strategies, except for molecular targeted therapy, which may be attributed to the limited number of studies. Therefore, the study revealed that pretreatment LMR might serve as a discriminative indicator for the prognoses of patients who undergo different therapeutic strategies.

The internal mechanisms of high pretreatment LMR associated with favorable outcomes of cancer patients remained unclear. The association may be explained through immune inflammation in the tumor microenvironment. It is well recognized that inflammation plays important roles in various cancers [2]. Tumor-infiltrating lymphocytes (TILs) and tumor-associated macrophages (TAMs) are common inflammatory cells in the tumor milieu that have been found to be prognostic factors [53-55]. TILs participate in cellular as well as humoral antitumor immune responses that contribute to tumor control. Furthermore, high numbers of TILs are associated with improved outcomes [56-59]. In addition, TILs are potential targets for cancer immunotherapy in several cancer types, including non-small-cell lung carcinoma, colorectal cancer, cutaneous $\mathrm{T}$ cell lymphoma and melanoma [57, 60-62]. Peripheral monocytes and myeloid progenitor cells differentiate into TAMs when entering tumors [14]. Shibutani et al. reported that the peripheral monocyte count is associated with the density of tumor-associated macrophages in the tumor microenvironment of colorectal cancer [12]. TAMs accelerate tumor progression and metastasis through production of growth factors and cytokines, which lead to angiogenesis and anti-immune responses [51, 52]. Studies indicated that high numbers of TAMs or pretreatment monocytes are associated with poor outcomes [14, 63-66]. Therefore, a high pretreatment LMR reflect a strong antitumor immunity in the tumor microenvironment and indicate latent therapeutic benefits for advanced-stage epithelial cancers.

Our study had several limitations. First, significant heterogeneity was observed among the included studies. Therefore, a random-effects model was used to adjust the heterogeneity in the analyses of OS and PFS. We also performed prespecified subgroup analyses to reduce the heterogeneity. Second, the number of studies included to assess the pretreatment LMR and outcomes undergoing different therapeutic strategies was limited, which could have led to the non-significant differences in subgroup analyses. Third, evidence of publication bias was inevitably observed, with fewer studies reporting negative results than would be expected. However, the random effects pooled HRs adjusted using the trim-and-fill methods did not shift the results in primary analysis. This suggests that our results are not biased by negative results. Moreover, HRs were available from only univariate analysis in 3 studies. These studies could lead to overestimation of the prognostic value of LMR, although sensitivity analysis indicated good stability of our results. Finally, the number of studies in the analysis of pretreatment LMR and PFS was small and the heterogeneity was also significant which may have biased our analysis.

Despite the above limitations, our meta-analysis supports the values of LMR as a promising independent predictor of survival in advanced epithelial cancer patients. Since LMR can be obtained from routine blood tests, intermediate assessments about changes in LMR during therapy are simply available. Therefore LMR could be used to improve clinical decision-making regarding treatment in advanced epithelial cancers.

\section{Conclusion}

Here, we searched online databases for relevant studies, and enrolled 35 studies with a total of 8984 patients for meta-analysis, drawing a conclusion that a high pretreatment LMR is associated with favorable survival with advanced-stage epithelial cancers undergoing different therapeutic strategies. A prospective trial is needed to identify LMR as a simple and readily available prognostic biomarker in clinical practice.

\section{Additional files}

Additional file 1. Additional tables.

Additional file 2: Figure S1. Funnel plot for meta-analysis of the association between pretreatment blood LMR and (A) overall survival, (B) overall survival adjusted with trim-and-fill methods.

\section{Authors' contributions}

Protocol/project development. YC, DC, YM, SD, CC. Data extraction and management: YM, DC, SD. Manuscript writing and editing: YM, DC, YZ, CW, FZ. All authors read and approved the final manuscript.

\section{Author details}

${ }^{1}$ Department of Thoracic Surgery, The Second Affiliated Hospital of Soochow University, 1055 Sanxiang Road, Gusu District, Suzhou 215004, China. ${ }^{2}$ Department of Thoracic Surgery, Shanghai Pulmonary Hospital, Tongji University, School of Medicine, 507 Zhengming Road, Yangpu District, Shanghai 200433, China. ${ }^{3}$ Department of Thoracic Surgery, Suzhou Kowloon Hospital, Shanghai Jiao Tong University School of Medicine, Suzhou, China. ${ }^{4}$ Department of Intensive Care Unit, Suzhou Kowloon Hospital, Shanghai Jiao Tong University School of Medicine, Suzhou, China. 


\section{Acknowledgements}

We thank International Science Editing (http://www.internationalscienceediti ng.com) for editing this manuscript.

\section{Competing interests}

The authors declare that they have no competing interests.

\section{Availability of data and materials}

The databases analyzed during the current study are available.

\section{Consent for publication}

Not applicable.

\section{Ethics approval and consent to participate}

Not applicable.

\section{Funds}

Supported by Jiangsu Provincial Commission of Health and Family Planning (Grant H201521), the Natural Science Foundation of Jiangsu Province (Grant BK20161224) and the Youth Science and technology project of Suzhou Health and Family Planning Commission (Grant KJXW2016016).

\section{Publisher's Note}

Springer Nature remains neutral with regard to jurisdictional claims in published maps and institutional affiliations.

Received: 25 September 2018 Accepted: 2 December 2018 Published online: 06 December 2018

\section{References}

1. Torre LA, Bray F, Siegel RL, Ferlay J, Lortet-Tieulent J, Jemal A. Global cancer statistics, 2012. CA Cancer J Clin. 2015;65(2):87-108. https://doi. org/10.3322/caac.21262.

2. Mei Z, Shi L, Wang B, Yang J, Xiao Z, Du P, Wang Q, Yang W. Prognostic role of pretreatment blood neutrophil-to-lymphocyte ratio in advanced cancer survivors: a systematic review and meta-analysis of 66 cohort studies. Cancer Treat Rev. 2017;58:1-13.

3. Chen YM, Lai CH, Chang HC, Chao TY, Tseng CC, Fang WF, Wang CC, Chung $\mathrm{YH}$, Wang $\mathrm{YH}$, Su MC, et al. Baseline and trend of lymphocyteto-monocyte ratio as prognostic factors in epidermal growth factor receptor mutant non-small cell lung cancer patients treated with first-line epidermal growth factor receptor tyrosine kinase inhibitors. PLoS ONE. 2015;10(8):e0136252.

4. Lin GN, Peng JW, Liu DY, Xiao JJ, Chen YQ, Chen XQ. Increased lymphocyte to monocyte ratio is associated with better prognosis in patients with newly diagnosed metastatic nasopharyngeal carcinoma receiving chemotherapy. Tumour Biol. 2014;35(11):10849-54.

5. Minami S, Ogata Y, Ihara S, Yamamoto S, Komuta K. Neutrophil-tolymphocyte ratio predicts overall survival of advanced non-small cell lung cancer harboring mutant epidermal growth factor receptor. World J Oncol. 2017;8(6):180-7.

6. Lin GN, Peng JW, Xiao JJ, Liu DY, Xia ZJ. Prognostic impact of circulating monocytes and lymphocyte-to-monocyte ratio on previously untreated metastatic non-small cell lung cancer patients receiving platinum-based doublet. Med Oncol. 2014;31(7):70.

7. Lin GN, Liu PP, Liu DY, Peng JW, Xiao JJ, Xia ZJ. Prognostic significance of the pre-chemotherapy lymphocyte-to-monocyte ratio in patients with previously untreated metastatic colorectal cancer receiving FOLFOX chemotherapy. Chin J Cancer. 2016;35:5. https://doi.org/10.1186/s4088 0-015-0025-7.

8. Xiong Y, Zhao N, Zheng Y, Wang J, Wei F, Ren X. Prognostic value of pretreatment inflammatory biomarkers in advanced lung adenocarcinoma patients receiving first-line pemetrexed/platinum doublet. Tumour Biol. 2017;39(6):1010428317701639.

9. Marin Hernandez C, Pinero Madrona A, Gil Vazquez PJ, Galindo Fernandez PJ, Ruiz Merino G, Alonso Romero JL, Parrilla Paricio P. Usefulness of lymphocyte-to-monocyte, neutrophil-to-monocyte and neutrophil-to-lymphocyte ratios as prognostic markers in breast cancer patients treated with neoadjuvant chemotherapy. Clin Transl Oncol. 2018;20(4):476-83

10. Neofytou K, Smyth EC, Giakoustidis A, Khan AZ, Williams R, Cunningham $D$, Mudan S. The preoperative lymphocyte-to-monocyte ratio is prognostic of clinical outcomes for patients with liver-only colorectal metastases in the neoadjuvant setting. Ann Surg Oncol. 2015;22(13):4353-62.

11. Qi Q, Zhuang L, Shen Y, Geng Y, Yu S, Chen H, Liu L, Meng Z, Wang P, Chen Z. A novel systemic inflammation response index (SIRI) for predicting the survival of patients with pancreatic cancer after chemotherapy. Cancer. 2016;122(14):2158-67.

12. Shibutani M, Maeda K, Nagahara H, Fukuoka T, Nakao S, Matsutani S, Hirakawa K, Ohira M. The peripheral monocyte count is associated with the density of tumor-associated macrophages in the tumor microenvironment of colorectal cancer: a retrospective study. BMC Cancer. 2017;17(1):404

13. Tanizaki J, Haratani K, Hayashi H, Chiba Y, Nakamura Y, Yonesaka K, Kudo K, Kaneda H, Hasegawa Y, Tanaka K, et al. Peripheral blood biomarkers associated with clinical outcome in non-small cell lung cancer patients treated with Nivolumab. J Thorac Oncol. 2018;13(1):97-105.

14. Kumagai S, Marumo S, Shoji T, Sakuramoto M, Hirai T, Nishimura T, Arima $\mathrm{N}$, Fukui M, Huang CL. Prognostic impact of preoperative monocyte counts in patients with resected lung adenocarcinoma. Lung Cancer. 2014;85(3):457-64.

15. Facciorusso A, Del Prete V, Crucinio N, Serviddio G, Vendemiale G, Muscatiello N. Lymphocyte-to-monocyte ratio predicts survival after radiofrequency ablation for colorectal liver metastases. World J Gastroenterol. 2016;22(16):4211-8.

16. Yang J, Guo X, Wang M, Ma X, Ye X, Lin P. Pre-treatment inflammatory indexes as predictors of survival and cetuximab efficacy in metastatic colorectal cancer patients with wild-type RAS. Sci Rep. 2017;7(1):17166.

17. Qi Q, Geng Y, Sun M, Wang P, Chen Z. Clinical implications of systemic inflammatory response markers as independent prognostic factors for advanced pancreatic cancer. Pancreatology. 2015;15(2):145-50.

18. Song A, Eo W, Lee S. Comparison of selected inflammation-based prognostic markers in relapsed or refractory metastatic colorectal cancer patients. World J Gastroenterol. 2015;21(43):12410-20.

19. Jiang R, Cai XY, Yang ZH, Yan Y, Zou X, Guo L, Sun R, Luo DH, Chen QY, Huang PY, et al. Elevated peripheral blood lymphocyte-to-monocyte ratio predicts a favorable prognosis in the patients with metastatic nasopharyngeal carcinoma. Chin J Cancer. 2015;34(6):237-46.

20. Zhu JY, Liu CC, Wang L, Zhong M, Tang HL, Wang H. Peripheral blood lymphocyte-to-monocyte ratio as a prognostic factor in advanced epithelial ovarian cancer: a multicenter retrospective study. J Cancer. 2017;8(5):737-43

21. Li SW, Yuan W, Zhao B, He ZK, Guo X, Xia WX, Xu LH. Positive effect of HPV status on prognostic value of blood lymphocyte-to-monocyte ratio in advanced cervical carcinoma. Cancer Cell Int. 2016;16:54.

22. Fukuda H, Takagi T, Kondo T, Shimizu S, Tanabe K. Predictive value of inflammation-based prognostic scores in patients with metastatic renal cell carcinoma treated with cytoreductive nephrectomy. Oncotarget. 2018;9(18):14296-305.

23. Li GJ, Ji JJ, Yang F, Xu HW, Bai Y. Preoperative lymphocyte-to-monocyte ratio predicts survival in primary hepatitis B virus-positive hepatocellular carcinoma after curative resection. Onco Targets Ther. 2017:10:1181-9.

24. Peng J, Li H, Ou Q, Lin J, Wu X, Lu Z, Yuan Y, Wan D, Fang Y, Pan Z. Preoperative lymphocyte-to-monocyte ratio represents a superior predictor compared with neutrophil-to-lymphocyte and platelet-to-lymphocyte ratios for colorectal liver-only metastases survival. Onco Targets Ther. 2017;10:3789-99.

25. Neal CP, Cairns V, Jones MJ, Masood MM, Nana GR, Mann CD, Garcea G, Dennison AR. Prognostic performance of inflammation-based prognostic indices in patients with resectable colorectal liver metastases. Med Oncol. 2015;32(5):144.

26. Wu QB, Wang M, Hu T, He WB, Wang ZQ. Prognostic role of the lymphocyte-to-monocyte ratio in patients undergoing resection for nonmetastatic rectal cancer. Medicine. 2016;95(44):e4945.

27. Gu L, Ma X, Wang L, Li H, Chen L, Li X, Zhang Y, Xie Y, Zhang X. Prognostic value of a systemic inflammatory response index in metastatic renal cell carcinoma and construction of a predictive model. Oncotarget. 2017:8(32):52094-103. 
28. Chang YP, Chen YM, Lai CH, Lin CY, Fang WF, Huang CH, Li SH, Chen HC, Wang CC, Lin MC. The impact of de novo liver metastasis on clinical outcome in patients with advanced non-small-cell lung cancer. PLoS ONE. 2017;12(6):e0178676.

29. Stotz M, Pichler M, Absenger G, Szkandera J, Arminger F, Schaberl-Moser R, Samonigg H, Stojakovic T, Gerger A. The preoperative lymphocyte to monocyte ratio predicts clinical outcome in patients with stage III colon cancer. Br J Cancer. 2014;110(2):435-40.

30. Kozak MM, von Eyben R, Pai JS, Anderson EM, Welton ML, Shelton AA, Kin C, Koong AC, Chang DT. The prognostic significance of pretreatment hematologic parameters in patients undergoing resection for colorectal cancer. Am J Clin Oncol. 2017:40(4):405-12.

31. Shibutani M, Maeda K, Nagahara H, Fukuoka T, Matsutani S, Kimura K, Amano R, Hirakawa K, Ohira M. The prognostic value of the systemic inflammatory score in patients with unresectable metastatic colorectal cancer. Oncol Lett. 2018;16(1):666-72. https://doi.org/10.3892/ ol.2018.8628.

32. Xue P, Hang J, Huang W, Li S, Li N, Kodama Y, Matsumoto S, Takaori K, Zhu $L$, Kanai M. Validation of lymphocyte-to-monocyte ratio as a prognostic factor in advanced pancreatic cancer: an East Asian Cohort Study of 2 countries. Pancreas. 2017;46(8):1011-7.

33. Zhou X, Du Y, Xu J, Huang Z, Qiu T, Wang X, Qian J, Zhu W, Liu P. The preoperative lymphocyte to monocyte ratio predicts clinical outcomes in patients with stage II/III gastric cancer. Tumour Biol. 2014;35(11):11659-66.

34. Chan JC, Chan DL, Diakos Cl, Engel A, Pavlakis N, Gill A, Clarke SJ. The lymphocyte-to-monocyte ratio is a superior predictor of overall survival in comparison to established biomarkers of resectable colorectal cancer. Ann Surg. 2017;265(3):539-46.

35. Oh SY, Kim YB, Suh KW. Prognostic significance of systemic inflammatory response in stage II colorectal cancer. J Surg Res. 2017;208:158-65.

36. Cong X, Li S, Xue Y. Impact of preoperative lymphocyte to monocyte ratio on the prognosis of the elderly patients with stage II-III gastric cancer. Chin J Gastrointest Surg. 2016;19(10):1144-8 (article in Chinese).

37. Kano S, Homma A, Hatakeyama H, Mizumachi T, Sakashita T, Kakizaki T, Fukuda S. Pretreatment lymphocyte-to-monocyte ratio as an independent prognostic factor for head and neck cancer. Head Neck. 2017;39(2):247-53.

38. Li GJ, Xu HW, Ji JJ, Yang F, Gao BQ. Prognostic value of preoperative lymphocyte-to-monocyte ratio in pancreatic adenocarcinoma. Onco Targets Ther. 2016;9:1085-92. https://doi.org/10.2147/OTT.S96707.

39. Moher D, Liberati A, Tetzlaff J, Altman DG, Grp P. Preferred reporting items for systematic reviews and meta-analyses: the PRISMA statement. Int J Surg. 2010;8(5):336-41.

40. Altman DG, Bland JM. How to obtain the confidence interval from a P value. BMJ. 2011;343:d2090.

41. Parmar MK, Torri V, Stewart L. Extracting summary statistics to perform meta-analyses of the published literature for survival endpoints. Stat Med. 1998;17(24):2815-34

42. Tierney JF, Stewart LA, Ghersi D, Burdett S, Sydes MR. Practical methods for incorporating summary time-to-event data into meta-analysis. Trials. 2007;8:16

43. Hayden JA, Cote P, Bombardier C. Evaluation of the quality of prognosis studies in systematic reviews. Ann Intern Med. 2006;144(6):427-37.

44. Jiang T, Qiao M, Zhao C, Li X, Gao G, Su C, Ren S, Zhou C. Pretreatment neutrophil-to-lymphocyte ratio is associated with outcome of advancedstage cancer patients treated with immunotherapy: a meta-analysis. Cancer Immunol Immunother. 2018;67(5):713-27. https://doi.org/10.1007/ s00262-018-2126-z.

45. Melsen WG, Bootsma MC, Rovers MM, Bonten MJ. The effects of clinical and statistical heterogeneity on the predictive values of results from meta-analyses. Clin Microbiol Infect. 2014;20(2):123-9.

46. Begg CB, Mazumdar M. Operating characteristics of a rank correlation test for publication bias. Biometrics. 1994;50(4):1088-101.

47. Egger M, Davey Smith G, Schneider M, Minder C. Bias in meta-analysis detected by a simple, graphical test. BMJ. 1997;315(7109):629-34.

48. Duval S, Tweedie R. Trim and fill: a simple funnel-plot-based method of testing and adjusting for publication bias in meta-analysis. Biometrics. 2000;56(2):455-63.

49. Yu SL, Xu LT, Qi Q, Geng YW, Chen H, Meng ZQ, Wang P, Chen Z. Serum lactate dehydrogenase predicts prognosis and correlates with systemic inflammatory response in patients with advanced pancreatic cancer after gemcitabine-based chemotherapy. Sci Rep. 2017;7:45194.

50. Liu X, Li M, Zhao F, Zhu Y, Luo Y, Kong L, Zhu H, Zhang Y, Shi F, Yu J. The lymphocyte-monocyte ratio predicts tumor response and survival in patients with locally advanced esophageal cancer who received definitive chemoradiotherapy. Onco Targets Ther. 2017;10:871-7.

51. Nishijima TF, Muss HB, Shachar SS, Tamura K, Takamatsu Y. Prognostic value of lymphocyte-to-monocyte ratio in patients with solid tumors: a systematic review and meta-analysis. Cancer Treat Rev. 2015;41(10):971-8.

52. Teng JJ, Zhang J, Zhang TY, Zhang S, Li BS. Prognostic value of peripheral blood lymphocyte-to-monocyte ratio in patients with solid tumors: a meta-analysis. Onco Targets Ther. 2016;9:37-47. https://doi.org/10.2147/ OTT.S94458.

53. Elinav E, Nowarski R, Thaiss CA, Hu B, Jin C, Flavell RA. Inflammationinduced cancer: crosstalk between tumours, immune cells and microorganisms. Nat Rev Cancer. 2013;13(11):759-71.

54. Smyth MJ, Ngiow SF, Ribas A, Teng MW. Combination cancer immunotherapies tailored to the tumour microenvironment. Nat Rev Clin Oncol. 2016;13(3):143-58.

55. Huang Y, Kim BYS, Chan CK, Hahn SM, Weissman IL, Jiang W. Improving immune-vascular crosstalk for cancer immunotherapy. Nat Rev Immunol. 2018;18(3):195-203.

56. Diem S, Schmid S, Krapf M, Flatz L, Born D, Jochum W, Templeton AJ, Fruh M. Neutrophil-to-lymphocyte ratio (NLR) and platelet-to-lymphocyte ratio (PLR) as prognostic markers in patients with non-small cell lung cancer (NSCLC) treated with nivolumab. Lung Cancer. 2017;111:176-81.

57. Pages F, Mlecnik B, Marliot F, Bindea G, Ou FS, Bifulco C, Lugli A, Zlobec I, Rau TT, Berger MD, et al. International validation of the consensus Immunoscore for the classification of colon cancer: a prognostic and accuracy study. Lancet. 2018;391(10135):2128-39.

58. Cannon NA, Meyer J, Iyengar P, Ahn C, Westover KD, Choy H, Timmerman R. Neutrophil-lymphocyte and platelet-lymphocyte ratios as prognostic factors after stereotactic radiation therapy for early-stage non-small-cell lung cancer. J Thorac Oncol. 2015;10(2):280-5.

59. Mahmoud SM, Paish EC, Powe DG, Macmillan RD, Grainge MJ, Lee AH, Ellis IO, Green AR. Tumor-infiltrating CD8+lymphocytes predict clinical outcome in breast cancer. J Clin Oncol. 2011;29(15):1949-55.

60. Durgeau A, Virk Y, Corgnac S, Mami-Chouaib F. Recent advances in targeting CD8 T-cell immunity for more effective cancer immunotherapy. Front Immunol. 2018;9:14.

61. Su H, Xie H, Dai C, Ren Y, She Y, Xu L, Chen D, Xie D, Zhang L, Jiang G, et al. Characterization of TIM-3 expression and its prognostic value in patients with surgically resected lung adenocarcinoma. Lung Cancer. 2018;121:18-24.

62. Anitei MG, Zeitoun G, Mlecnik B, Marliot F, Haicheur N, Todosi AM, Kirilovsky A, Lagorce C, Bindea G, Ferariu D, et al. Prognostic and predictive values of the immunoscore in patients with rectal cancer. Clin Cancer Res. 2014;20(7):1891-9. https://doi.org/10.1158/1078-0432.CCR-13-2830.

63. Li Z, Maeda D, Yoshida M, Umakoshi M, Nanjo H, Shiraishi K, Saito M, Kohno T, Konno H, Saito H, et al. The intratumoral distribution influences the prognostic impact of CD68- and CD204-positive macrophages in non-small cell lung cancer. Lung Cancer. 2018;123:127-35.

64. Zhu Y, Li M, Bo C, Liu X, Zhang J, Li Z, Zhao F, Kong L, Yu J. Prognostic significance of the lymphocyte-to-monocyte ratio and the tumor-infiltrating lymphocyte to tumor-associated macrophage ratio in patients with stage T3NOMO esophageal squamous cell carcinoma. Cancer Immunol Immunother. 2017;66(3):343-54. https://doi.org/10.1007/s00262-016-1931-5.

65. Shen M, Chen Y, Xu L, Zhu R, Xue X, Tsai Y, Keng PC, Lee SO, Chen Y. Increased infiltration of macrophages to radioresistant lung cancer cells contributes to the development of the additional resistance of tumor cells to the cytotoxic effects of NK cells. Int J Oncol. 2018;53(1):317-28. https://doi.org/10.3892/ijo.2018.4394.

66. Cassetta L, Kitamura T. Targeting tumor-associated macrophages as a potential strategy to enhance the response to immune checkpoint inhibitors. Front Cell Dev Biol. 2018;6:38. 